\title{
Interposition Technique for Septal Perforation Using a Composite Graft Made Up of Allograft Dermal Matrix and Autologous Cartilage
}

\author{
Dong Young Kim, Joo Yeon Kim ${ }^{1}$, Jun Sang Cha ${ }^{D}$, and Jae Hwan Kwon (D) \\ Department of Otolaryngology-Head and Neck Surgery, Kosin University College of Medicine, Busan, Korea
}

동종 진피이식물과 자가연골 복합체를 이용한 비중격 천공의 재건술

김동영 · 김주연 · 차준상 · 권재환

고신대학교 의과대학 이비인후과학교실

Received July 12, 2021

Revised September 2, 2021

Accepted September 6, 2021

Address for correspondence

Jae Hwan Kwon, MD, PhD

Department of Otolaryngology-

Head and Neck Surgery,

Kosin University

College of Medicine,

Kosin University Gospel Hospital,

262 Gamcheon-ro, Seo-gu,

Busan 49267, Korea

Tel +82-51-990-6138

Fax +82-51-245-8539

E-mail entkwon@hanmail.net
Background and Objectives Interposition using acellular allograft between perforated septal flaps is a popular procedure among surgeons because of its usefulness. However, allograft dermal matrix itself tends to become infected sometimes, and can easily undergo necrosis or be displaced from the implanted site. Here, the authors would like to introduce a newly devised interposition graft made up of allograft and cartilage, which is easy to manipulate and can be fixed in the desired position.

Subjects and Method We performed a retrospective chart review from January 2018 to August 2020. A total of 12 patients with septal perforation who received surgical treatment were included in this study. Acellular human dermal allograft (MegaDerm ${ }^{\circledR}$; L\&C Bio) was used as an interposition allograft piled up by autologous cartilage, and it was positioned between the mucoperichondrial flaps via the endonasal approach.

Results The most common etiology was previous septal surgery $(n=8)$; in one case, the etiology was repeated electrocauterization due to frequent epistaxis; the etiology was not verified for three cases. All 12 cases achieved the result of complete septal perforation closure. All patients on follow-up inquiry reported marked improvements in the visual analogue scale score (mean value, 4.1 to 1) and Nasal Obstruction Symptom Evaluation scale (mean value, 7.3 to 1.8). Conclusion Composite graft made up of cartilage and allograft dermal matrix achieved successful results without having to fix the graft. It can be an alternative technique to treat septal perforation for inexperienced surgeons and with a limited operation field.

Korean J Otorhinolaryngol-Head Neck Surg 2022;65(1):24-9

Keywords Allograft; Nasal septal perforation; Septoplasty.

\section{Introduction}

Septal perforation is a condition defined by loss of septal cartilage or bony structure along with the defect in bilateral septal mucosa. ${ }^{1)}$ Disruption of blood supply to the septum is

This is an Open Access article distributed under the terms of the Creative Commons Attribution Non-Commercial License (https://creativecommons.org/licenses/by-nc/4.0) which permits unrestricted non-commercial use, distribution, and reproduction in any medium, provided the original work is properly cited. the most common cause after septal surgery and cauterization for epistaxis. Granulomatous disease or cocaine abuse, chromic acid fumes, and arsenic are the recognized causes of septal perforation. Most of the septal perforations are asymptomatic, and they do not require any treatment. However, patients who complain of irritating symptoms, such as nasal obstruction and epistaxis, need treatment. ${ }^{2)}$ Conservative treatments, which include nasal irrigation and ointment, can reduce the 
nasal symptoms, but the cases which do not improve with medical treatments need other treatments.

Closing the perforation site with a septal button can be an alternative method ahead to surgical closure. ${ }^{3)}$ However, designing a rigid septal button fitting into the curvature of the septum is a challenging task, and it irritates the surrounding tissue, forms a crust, and causes secondary infection. Also, the patient compliance is very low. ${ }^{4}$

If medical treatments cannot alleviate the symptoms, surgical treatments should be applied. Numerous techniques for closing the perforation have been introduced, but most of them are technically challenging and troublesome for surgeons in a narrow operation field.

In this article, we would like to introduce interposition of a composite graft made up of autologous cartilage and acellular dermal matrix for closing a septal perforation, which is a simple and novel technique.

\section{Subjects and Methods}

A retrospective chart review was conducted, and 12 patients who had been treated for septal perforation in Kosin University Gospel Hospital were included. All patients complained of septal perforation-associated symptoms. Septal perforation was diagnosed by endoscopic examination. Nine patients were males, and the remaining 3 patients were female. The patient age ranged from 20 years to 61 years (mean value, 34.1 years). The patients' symptoms were noted by the visual analogue scale (VAS) analog scale and NOSE scale. Ethical approval for this study was granted by the Institutional Review Board of Kosin University Gospel Hospital (2020-06-039).

\section{Surgical procedure}

All patients underwent surgery via an external approach or an endoscopic assisted endonasal approach. A columellar incision was made for the external approach aligned with a marginal incision. All cases that underwent the endonasal approach were accessed via a hemitransfixion incision on the concave side. Mucoperichondrial flaps were raised around the perforation site, and the granulation tissue or scar around the perforation was trimmed meticulously. Septoplasty was performed in all cases. The remnant septal cartilage was harvested for a composite graft. If the harvested septal cartilage was not sufficient, additional cartilage was harvested from the conchal or rib cartilage. The septum, concha, and rib cartilage were harvested in 3 cases, 8 cases, and 1 case, respectively (Table 1). We made the interposition graft using MegaDerm ${ }^{\circledR}$ (L\&C Bio, Seoul, Korea) and harvested cartilage. The operator trimmed the fully hydrated MegaDerm ${ }^{\circledR}$, slightly larger than the perforation site, and the harvested cartilage was trimmed to a size similar to the perforation. MegaDerm ${ }^{\circledR}$ was stacked up with the harvested cartilage, and it was fixed by a simple interrupted mattress suture using 5-0 polydioxanone (Fig. 1). A composite graft was positioned between the mucoperichondrial flap, and unilateral septal mucosa was designed to create an advanced flap and was sutured to close the perforation in 2 cases, in which the opposite side of the graft was left to be exposed. In the other 10 cases, perforation sites were not closed by a suture, and grafts were left to be exposed. No further procedure was performed to fix the graft except for placing the

Table. 1. Baseline clinical and demographic characteristics of patients with septal perforation $(n=12)$

\begin{tabular}{|c|c|c|c|c|c|c|c|}
\hline No & Sex/age & Cause & $\begin{array}{l}\text { Time elapsed from } \\
\text { the occurrence }(\mathrm{yr})\end{array}$ & $\begin{array}{c}\text { Size }(H L \times V L) \\
(\mathrm{mm})\end{array}$ & $\begin{array}{c}F / U \\
\text { (week) }\end{array}$ & $\begin{array}{c}\text { Harvested } \\
\text { cartilage }\end{array}$ & Incision \\
\hline $1^{*}$ & $M / 44$ & Unknown & - & $10 \times 8$ & 14.4 & Concha & Hemitransfixion \\
\hline $2^{*}$ & $M / 33$ & Septoplasty & 8 & $14 \times 10$ & 12.6 & Concha & Hemitransfixion \\
\hline 3 & $M / 26$ & Septoplasty & 5 & $3 \times 3$ & 26.6 & Rib & Hemitransfixion \\
\hline 4 & $\mathrm{~F} / 20$ & Septoplasty & 4 & $4 \times 5$ & 12.0 & Septum & Hemitransfixion \\
\hline 5 & $M / 26$ & Septoplasty & 6 & $10 \times 7$ & 60.1 & Concha & Hemitransfixion \\
\hline 6 & $F / 21$ & Unknown & - & $13 \times 12$ & 16.1 & Septum & Columellar \\
\hline 7 & M/25 & Septoplasty & 8 & $8 \times 7$ & 24.9 & Concha & Hemitransfixion \\
\hline 8 & $M / 61$ & Unknown & - & $4 \times 4$ & 12.1 & Septum & Columellar \\
\hline 9 & M/25 & Septoplasty & 1 & $4 \times 4$ & 12.9 & Concha & Hemitransfixion \\
\hline 10 & $M / 48$ & Septoplasty & 2 & $5 \times 7$ & 13.1 & Concha & Hemitransfixion \\
\hline 11 & $M / 56$ & Septoplasty & 5 & $10 \times 9$ & 14.6 & Concha & Hemitransfixion \\
\hline $12^{+}$ & $F / 24$ & Cauterization & - & $17 \times 15$ & 13.0 & Concha & Hemitransfixion \\
\hline
\end{tabular}

* cases using an unilateral advancement flap to close the perforation; this patient showed septal reperforation and nasal dorsal depression 3 months after surgery. HL, horizontal length; VL, vertical length; F/U, follow up 
composite graft between mucoperichondrial flaps (Fig. 2). The hemitransfixion incision was sutured by absorbable thread. Silastic sheets were positioned bilaterally and removed 3 weeks after the operation.

\section{Postoperative care}

The patients were given intravenous broad-spectrum antibiotics. Saline nasal irrigation was started to keep the nose moist at 3 days after the operation. Silastic sheets were removed 3 weeks after the operation. Endoscopic inspection of the nasal cavity was performed after silastic sheet removal, and 6 and 12 weeks after the operation. The postoperative patients' symptoms were described by the VAS analog scale and NOSE scale at 6-12 weeks postoperatively.

\section{Results}

The most common etiology was previous septal surgery $(n=8)$, one case occurred due to repeated chemical cauterization of the septum, and we could not establish the definite etiologies in the remaining 3 cases. The mean follow-up was 19.4 weeks with a minimum of 12 weeks of follow-up. Septal per-

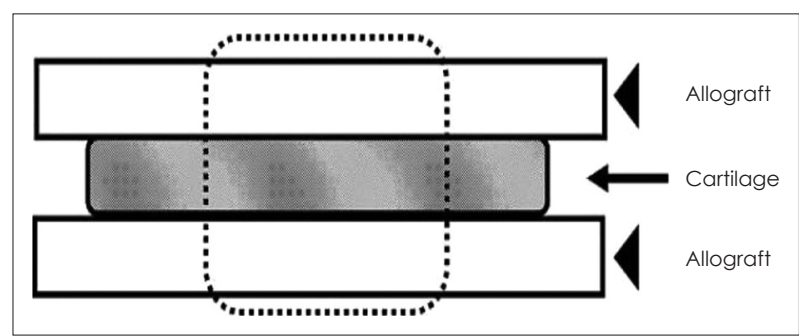

Fig. 1. Schematic figure shows how to make a composite graft. It is fixed by a simple horizontal mattress suture (dotted line).

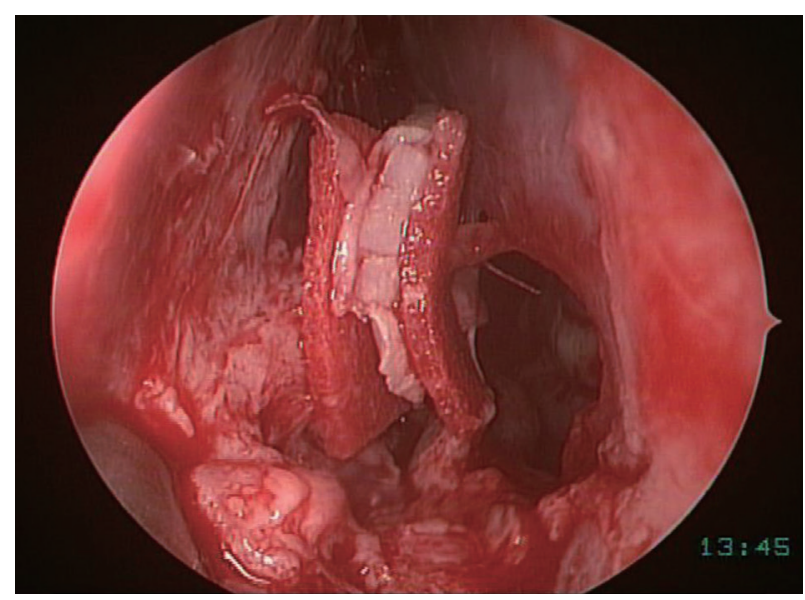

Fig. 2. Composite graft made up of autologous cartilage and Mega$\operatorname{Derm}^{\circledast}(\mathrm{L} \& \mathrm{C} \mathrm{Bio})$ is placed at the perforated site between nasal septal flaps. forations ranged from 3 to $17 \mathrm{~mm}$ in horizontal length (mean value, $8.5 \mathrm{~mm}$ ) and from 3 to $15 \mathrm{~mm}$ in vertical length (mean value, $7.6 \mathrm{~mm}$ ). A unilateral advancement flap was created and sutured to close the perforation in 2 cases. Eight cases received conchal cartilage as the graft material, 3 cases received septal cartilage, and 1 case received rib cartilage (Table 1). Complete closure was achieved in all cases except one case, and grafts were covered by normal nasal mucosa 3 months after surgery. One patient (No.12) with perforation size $17 \mathrm{~mm}$ showed septal reperforation and saddle nose deformity. However, the size of the perforated septum was much smaller than that before surgery, and the patient's nasal symptom was greatly improved. The mean VAS score was reduced from 4.1 (range $2-6$ ) to 1 (range $0-3$ ) (Fig. 3), and the NOSE scale was reduced from 7.3 (range 4-11) to 1.8 (range 0-6) (Fig. 4). Representative cases are shown in Figs. 5 and 6.

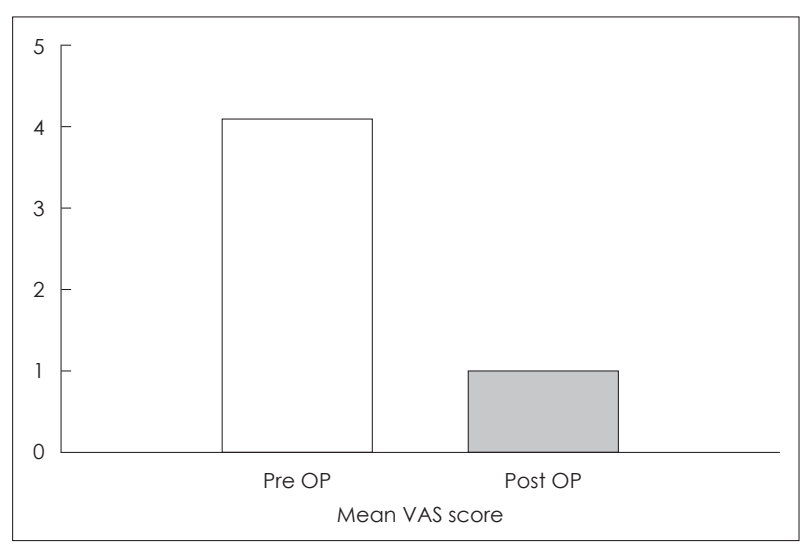

Fig. 3. Pre and post OP VAS score. The pre OP mean VAS score (4.1, ranging from 2 to 6$)$ was statistically reduced postoperatively (1.0, ranging from 0 to 4$)$. OP, operative; VAS, visual analogue scale.

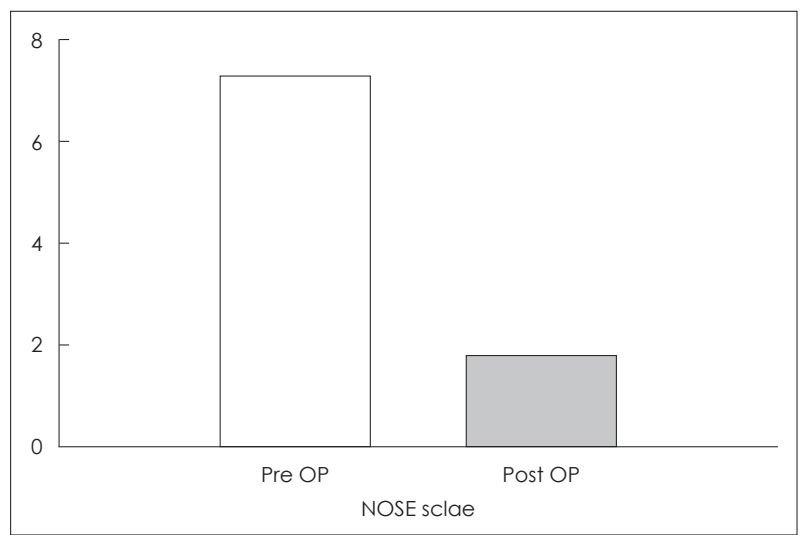

Fig. 4. Pre and post OP NOSE scale score. The pre OP mean NOSE scale score $(7.8$, ranging from 4 to 11$)$ was statistically reduced postoperatively (1.8, ranging from 0 to 6$)$. OP, operative; NOSE, Nasal Obstruction Symptom Evaluation. 

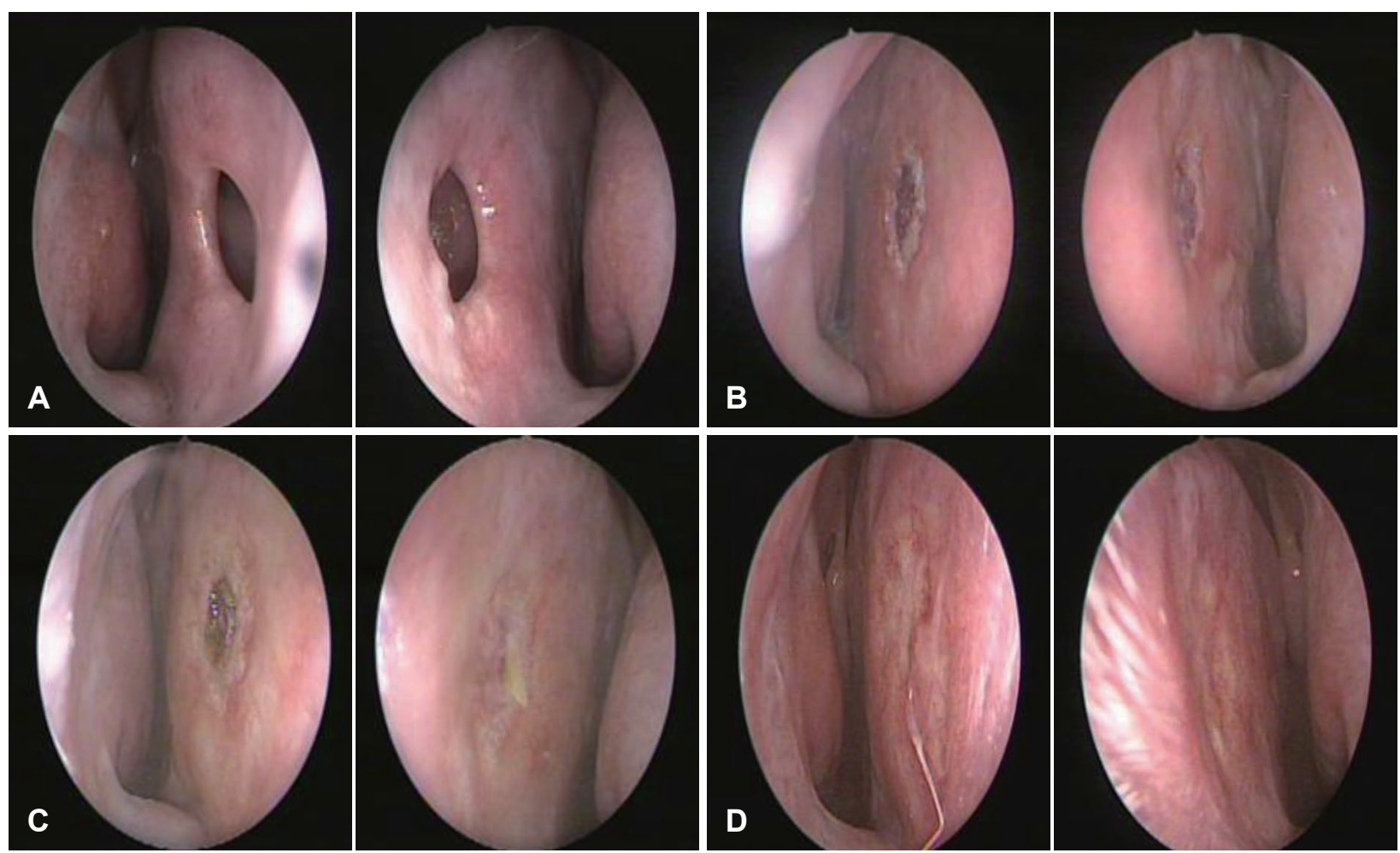

Fig. 5. A 44-year-old male was diagnosed with septal perforation of size $10 \mathrm{~mm}$ (case No. 1, Table 1). We conducted surgical closure via an endonasal approach by interposition of cartilage and MegaDerm ${ }^{\circledR}$ (L\&C Bio) composite graft without fixation of the graft. A-C: The preoperative right and left endonasal view of the perforation site (A) showed a healing state with granulomatous change 3 weeks (B), 6 weeks (C), after the operation. D: After 12 months, the perforation was completely closed with secondary mucosal healing.
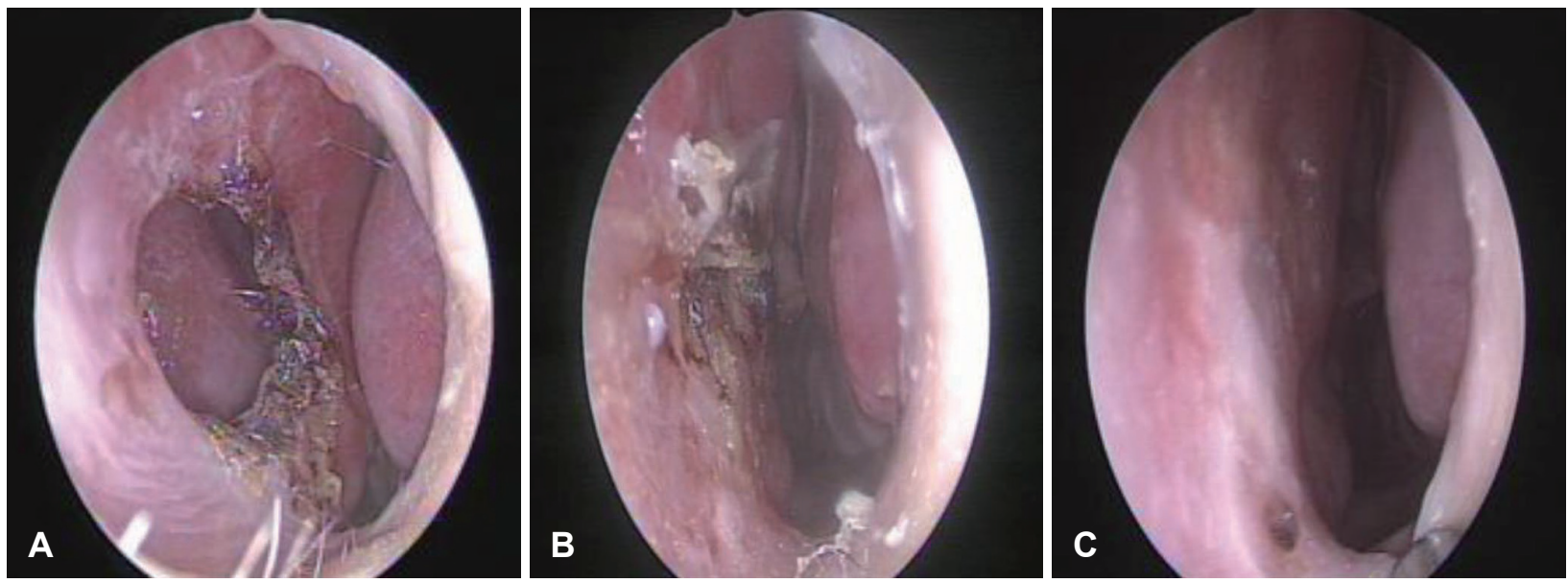

Fig. 6. A 31-year-old male was diagnosed with septal perforation of size $14 \mathrm{~mm}$ (case No. 2, Table 1). The patient underwent surgery via an external approach with a left side advanced flap to close the perforation. A: The preoperative left endoscopic view of septal perforation. B: Three weeks after surgery, it showed a healing state with crust formation. C: After postoperative 3 months, the septal perforation was completely closed.

\section{Discussion}

Numerous techniques for surgical closure of septal perforation have been introduced since Teichgraeber and Russo ${ }^{5)}$ described the management of septal perforations in 1993. Because of the limited endoscopic vision and narrow operation field, an external approach is favored in cases with large per- foration. However, an external approach may create an additional scar at the incision site and require a longer healing time compared with endonasal and endoscopic approaches. ${ }^{6}$ Therefore, in cases with small perforation size, we could derive the benefit of the endoscopic assisted endonasal approach. Many papers have mentioned about the materials for closing a septal perforation. It is well- documented that a porcine small in- 
testine submucosal graft improves remucosalization of the upper airway tract, but a porcine allergic reaction and resorption are likely problems. ${ }^{7,8)}$ A polydioxanone plate is also firm and easy to manipulate, and it is readily usable without the harvesting procedure. ${ }^{9)}$ The majority of surgeons routinely adopt an interposition graft, and acellular dermis is the most popular material for the interposition graft.

Cartilage is the second most frequently used graft, followed by temporalis fascia, polydioxanone plate, and porcine intestinal submucosa. ${ }^{8)}$ Cartilage is a widely used graft for closing septal perforation, ${ }^{10-12)}$ and autologous cartilage is safer than additional commercialized products. However, cartilage may get displaced because of its smooth surface although it is a strong barrier, and acellular allograft dermal matrix is thin and vulnerable to inflammation. Therefore, we designed a composite graft consisted of autologous cartilage and acellular allograft dermal matrix to compensate for the shortcomings of each graft.

Kridel, et al. ${ }^{13)}$ introduced acellular dermis for interposition grafting. They directly sutured the graft to the remnant septal structure via an external approach. In most of their cases, but they used a bilateral advancement flap. Asyford, et al. ${ }^{14)}$ successfully conducted this method by the endoscopic approach, but a suture is needed to fix the graft to the remnant septal structure in the limited view and operation field. In the previous two studies, it was not interposition graft, but allograftonly repair, so all cases had to be considered for unilateral or bilateral advancement flaps to increase the success rate. ${ }^{13,14)}$

However, in this study, except for the two cases in which size was considered large, the result was sufficiently successful without the advancement flaps. Especially, the endoscopic operation imposes one hand surgery upon the surgeons, which is difficult for inexperienced surgeons. Several studies have reported that the authors sutured a graft to the mucoperichondrial flap, ${ }^{15,16)}$ and it could be easier than suturing it to hard cartilage or bone. However, it does not change the fact that surgeons still need to perform a suture in a narrow nasal cavity. Parry, et al. ${ }^{17)}$ introduced another way to fix the graft, in which they applied fibrin glue to the graft and successfully fixed it in the appropriate position. However, another paper reported that fibrin glue could cause segmental cartilage loss in rabbits. ${ }^{18)}$ Other studies showed great success in closing the perforation by combining autologous cartilage or temporalis muscle fascia. ${ }^{9,19,20)}$ However, it still needs to be sutured in place for anchoring at the perforation site, and additional mucosal injury may occur, which may result in resorption several weeks later. ${ }^{21)}$ In this study, the composite graft helped us to skip the suture procedure; we simply placed the graft in the appropriate position after elevating the flaps around the perforation site. It is because our composite graft is designed both side allograft materials that has micropore on the surface and therefore risk of displacement is low.

We performed most of the surgeries via an endonasal approach, except for two cases, without suturing the graft in the limited endonasal view. It required a relatively short operation time, and all cases showed excellent results postoperatively. This suggests that in cases with small to medium sized septal perforation, the perforation need not be fully covered with septal flaps, and complete closure can be achieved via the secondary healing procedure.

There are some limitations to this study. First, the size of septal perforation in this study was relatively small to medium. One patient in this study showed septal reperforation after surgery, and the perforation size was relatively large $(17 \times 15$ mm, No. 12 in Table 1). Further study is needed for large septal perforations. Second, more cases should be collected to develop an appropriate operation technique according to the perforation size. Finally, long-term viability should be studied in subsequent studies.

In conclusion, septal perforation usually occurs after septoplasty. In this study, the authors applied the interposition technique using a composite graft made up of autologous cartilage and acellular dermis without fixation to close the septal perforation. This may be a novel technique for septal perforation surgery, and it may provide an easy surgical method with good results.

\section{Acknowledgments}

None.

\section{Author Contribution}

Conceptualization: Joo Yeon Kim, Jae Hwan Kwon. Data curation: Jun Sang Cha. Formal analysis: Jae Hwan Kwon. Methodology: Joo Yeon Kim, Jae Hwan Kwon. Supervision: Jae Hwan Kwon. Writing — original draft: Dong Young Kim. Writing — review \& editing: Jun Sang Cha.

\section{ORCIDs}

Jae Hwan Kwon

Joo Yeon Kim

https://orcid.org/0000-0002-3260-6969

Jun Sang Cha

https://orcid.org/0000-0002-6543-6775

\section{REFERENCES}

1) Downs BW, Sauder HM. Septal Perforation. StatPearls [online] 2021 Aug 7 [cited 2021 May 5]. Available from: URL: https://www. ncbi.nlm.nih.gov/books/NBK537208/.

2) Schultz-Coulon HJ. [Nasal septum repair-plasty with pedicled flap 
technique in 126 patients--an analysis]. Laryngorhinootologie 1997;76(8):466-74.

3) Osma U, Cüreoğlu S, Akbulut N, Meriç F, Topçu I. The results of septal button insertion in the management of nasal septal perforation. J Laryngol Otol 1999;113(9):823-4.

4) Eliachar I, Mastros NP. Improved nasal septal prosthetic button. Otolaryngol Head Neck Surg 1995;112(2):347-9.

5) Teichgraeber JF, Russo RC. The management of septal perforations. Plast Reconstr Surg 1993;91(2):229-35.

6) Kim HC, Jang YJ. Columellar incision scars in Asian patients undergoing open rhinoplasty. JAMA Facial Plast Surg 2003;18(3): 188-93.

7) Kridel RW. Considerations in the etiology, treatment, and repair of septal perforations. Facial Plast Surg Clin North Am 2004;12(4): 435-50.

8) Nayak JV, Rathor A, Grayson JW, Bravo DT, Velasquez N, Noel J, et al. Porcine small intestine submucosal grafts improve remucosalization and progenitor cell recruitment to sites of upper airway tissue remodeling. Int Forum Allergy Rhinol 2018;8(10): $1162-8$.

9) Epprecht L, Schlegel C, Holzmann D, Soyka M, Kaufmann T. Closure of nasal septal perforations with a polydioxanone plate and temporoparietal fascia in a closed approach. Am J Rhinol Allergy 2017;31(3):190-5.

10) Fairbanks DN. Closure of nasal septal perforations. Arch Otolaryngol 1980;106(8):509-13

11) Kridel RW, Appling WD, Wright WK. Septal perforation closure utilizing the external septorhinoplasty approach. Arch Otolaryngol Head Neck Surg 1986;112(2):168-72.

12) Woolford TJ, Jones NS. Repair of nasal septal perforations using local mucosal flaps and a composite cartilage graft. J Laryngol
Otol 2001;115(1):22-5.

13) Kridel RW, Foda H, Lunde KC. Septal perforation repair with acellular human dermal allograft. Arch Otolaryngol Head Neck Surg 1998;124(1):73-8.

14) Ayshford CA, Shykhon M, Uppal HS, Wake M. Endoscopic repair of nasal septal perforation with acellular human dermal allograft and an inferior turbinate flap. Clin Otolaryngol Allied Sci 2003; 28(1):29-33.

15) Lee KC, Lee NH, Ban JH, Jin SM. Surgical treatment using an allograft dermal matrix for nasal septal perforation. Yonsei Med J 2008;49(2):244-8.

16) Pae SY, Moon KR, Park HS, Lee SS. A case of septal perforation reconstructed with alloderm interposition graft resulted from magnetic nasal foreign bodies. Korean J Otorhinolaryngol-Head Neck Surg 2009;52(3):262-5.

17) Parry JR, Minton TJ, Suryadevara AC, Halliday D. The use of fibrin glue for fixation of acellular human dermal allograft in septal perforation repair. Am J Otolaryngol 2008;29(6):417-22.

18) Erkan AN, Cakmak O, Kocer NE, Yilmaz I. Effects of fibrin glue on nasal septal tissues. Laryngoscope 2007;117(3):491-6.

19) Morse J, Harris J, Owen S, Sowder J, Stephan S. Outcomes of nasal septal perforation repair using combined temporoparietal fascia graft and polydioxanone plate construct. JAMA Facial Plast Surg 2019;21(4):319-26.

20) Sand JP, Desai SC, Branham GH. Septal perforation repair using polydioxanone plates: A 10-year comparative study. Plast Reconstr Surg 2015;136(4):700-3.

21) Boenisch M, Tamás H, Nolst Trenité GJ. Influence of polydioxanone foil on growing septal cartilage after surgery in an animal model: New aspects of cartilage healing and regeneration (preliminary results). Arch Facial Plast Surg 2003;5(4):316-9. 